\title{
El capitán Francisco Iglesias Brage en Leticia. Un gallego properuano en la Comisión de Administración del Territorio (1933-1934)
}

\author{
Pedro López Gómez \\ Departamento de Biblioteconomía y Documentación, \\ Universidad de A Coruña
}

\begin{abstract}
Aproximación a los litigios fronterizos entre Perú y Colombia, en especial al contencioso sobre el "Trapecio de Leticia", en cuya administración tuvo papel destacado, por mandato de la Sociedad de Naciones, el Coronel de Aviación D. Francisco Iglesias Brage, entonces Capitán (Ferrol, 21 de mayo de 1900-Madrid, 14 de marzo de 1973).'
\end{abstract}

\section{Introducción: la ocupación de Leticia}

En la noche del 31 de agosto al 1 de septiembre de 1932, un grupo de individuos armados, de nacionalidad peruana, ocupó el puerto fluvial de Leticia, capital del distrito colombiano del Amazonas. La población de Leticia tenía por aquellas fecha unos trescientos habitantes.

Los asaltantes, que ocuparon seguidamente el territorio conocido como "Trapecio de Leticia", situado entre el Putumayo y el Amazonas, fortificaron en ese territorio una serie de posiciones sobre los dos ríos. Los habitantes de nacionalidad colombiana debieron buscar refugio en territorio brasileño.

A fin de restablecer el orden público en el territorio invadido, el Gobierno colombiano armó una flotilla que se dirigió, primero por mar, y después por vía fluvial, a dicho territorio. Hizo escala en diversos puertos del Amazonas, remontó el río, una parte para dirigirse por el Putumayo al norte del trapecio, y la otra parte hacia el sur, por el Amazonas mismo. La expedición estaba integrada por unos 1.500 hombres y 6 unidades. Llegó a las aguas colombianas el 12 de febrero de 1933. El Gobierno colombiano organizó también otras expediciones por vías terrestre y aérea con finalidad militar.

1 Este trabajo es una revisión actualizada, con motivo del reciente centenario del nacimiento de Iglesias Brage, de López Gómez, Pedro: El Capitán Iglesias en el Trapecio de Leticia. Su comisión en la Administración del Territorio por la Sociedad de Naciones (1933-1934). Madrid, Universidad Complutense. Cursos de Doctorado, 1980-1981, 65 fol., mec., il., map. 
Por su parte, los ocupantes peruanos del territorio colombiano fueron sostenidos en su iniciativa por el Comandante General de la Quinta región militar peruana. Éste dirigió, el 6 de enero de 1933, una comunicación al cónsul general de Colombia en Belem do Pará (Brasil), y al jefe de las fuerzas expedicionarias colombianas, que finalizaba así:

\begin{abstract}
"He tomado todas las medidas de carácter militar para impedir la entrada de vuestra expedición a Leticia y para garantizar nuestra seguridad en la cuenca del Amazonas peruano, a fin de impedir actos de hostilidad contra mis compatriotas que ocupan legítimamente la zona de Leticia, apoyados en los principios enunciados de libre determinación de la nacionalidad".
\end{abstract}

El 12 de febrero, la flotilla colombiana se encontraba cerca de la línea fronteriza entre Brasil y Colombia. Fue atacada por aviones peruanos, que fueron a su vez contraatacados por aviones colombianos. No se comprobó si estos enfrentamientos tuvieron ó no lugar en territorio brasileño.

El 14 de febrero, el jefe de la expedición colombiana dirigió un ultimátum a un puesto peruano establecido en Tarapaca, en territorio colombiano. Según informaciones colombianas se tomó un importante material de guerra. Como consecuencia de estos incidentes, las relaciones diplomáticas entre los dos países se rompieron el día 15.

El 23 de febrero, el gobierno colombiano hizo saber que aviones militares peruanos habían bombardeado los navíos de la expedición colombiana. Finalmente, y por carta del 27 de febrero, el representante de Colombia denunciaba que las fuerzas colombianas eran continuamente molestadas por las guarniciones peruanas en el Alto Putumayo, que forma frontera entre los dos países en esta región.

Después de estas confrontaciones, se abrió un período de conciliación, que tuvo por eje la mediación de Brasil primeramente, y que fracasó, declarándolo cerrado el Ministro de Asuntos Extranjeros brasileño el 3 de febrero de 1933.

Se abrió entonces otro intento de conciliación por medio de la Sociedad de Naciones, a partir de la comunicación del delegado de Colombia al Secretario General de "incidentes provocados por la perturbación del orden en una de las partes del territorio colombiano en la región del Amazonas", el 2 de enero. Sucesivas comunicaciones de Perú sobre la inaplicabilidad del Tratado de 1922, y de Ecuador sobre sus derechos en la cuenca del Amazonas, y peticiones peruanas de que el Consejo ordenara la suspensión de toda medida de fuerza, culminaron con la creación de un 
comité formado por representantes del Estado libre de Irlanda, de España y de Guatemala, y tras nuevas negociaciones, el Consejo recomendaba:

- La evacuación completa del territorio comprendido en el Trapecio de Leticia por las fuerzas peruanas, así como la retirada de todo apoyo a los elementos peruanos que ocuparon esa región.

- Que las negociaciones fuesen entabladas y proseguidas con la mayor diligencia desde el momento en que se tomasen las medidas prácticas para la ejecución de la primera recomendación. ${ }^{2}$

Finalmente, el 25 de mayo de 1933, se firmaba en Ginebra un acuerdo entre los representantes de los gobiernos de los dos países, aceptando las modalidades de ejecución de las soluciones propuestas por el Consejo en el informe de 18 de marzo, tal como fueron recomendadas por el Comité consultivo y aprobadas por el Consejo en su sesión del 23 de mayo.

El acuerdo constaba de ocho puntos, e incluía el nombramiento de una Comisión que se haría cargo de la administración del Territorio de Leticia, en nombre del Gobierno de Colombia, y de donde se retirarían las fuerzas peruanas. Esta Comisión, que se encontraría en Leticia en un plazo de 30 días, utilizaría las fuerzas militares necesarias, y tendría una duración máxima de un año. Los gastos correrían a cargo del Gobierno de Colombia. Ambos países se comprometían a cesar en los actos de hostilidad entre ellos. ${ }^{3}$

Vamos a analizar la actuación de la Comisión, centrándonos en la figura de Iglesias Brage, y teniendo presente sobre todo los aspectos políticos y administrativos de los sucesos. Pero no se podría entender el conflicto de Leticia sin remontarse atrás en el tiempo, hasta llegar a la época de la dominación española, y especialmente necesario es detenerse en el tratado Salomón-Lozano, de 1922, clave de los sucesos que narramos.

\section{Antecedentes: los litigios fronterizos entre Perú y Colombia}

Los litigios fronterizos entre los dos países andinos se arrastraban desde la época de la dominación española, al igual que ocurre en el resto de

2 Archivo Iglesias Brage (en adelante, IB), legajo 145 (3). Société des Nations. Communiqué au Conseil et aux Membres de la Societé. Différend entre la Colombie et le Pérou: Appel de la Colombie aux termes de l'article 15 du pacte. Série de Publications de la Société des Nations. VII. Questions politiques. 1933. 3 (N. ${ }^{\circ}$ officiel: C. 194. M. 91.1933.VII).

3 IB, 145 (3). Société des Nations. Comuniqué au Conseil et aux Membres de la Société. Differend entre la Colombie et le Perou. Appel de la Colombie aux termes de l'article 15 du pacte. C. 336. M. 161. 1933. VII. 
las naciones hispanoamericanas, como consecuencia de la conversión en fronteras de las anteriores delimitaciones administrativas, no muy precisas y variables en el tiempo.

En el caso peruano tendrán un intento de solución definitiva con el Tratado Salomón-Lozano, de 1922. ${ }^{4}$ Este tratado ha de ser contemplado, sin embargo, no sólo como el resultado final de unas tensiones motivadas por factores económicos, sociales, políticos, diplomáticos y militares, sino - y sobre todo- como resultado de la política norteamericana en su "huerto al sur de Río Grande", que si bien se vislumbra como una sombra difusa pero perceptible detrás de todo acontecimiento relevante, a veces se manifiesta con todo descaro mediante intervenciones militares o presiones políticas como ésta a la que nos referimos.

El Tratado Salomón-Lozano ha de entenderse, según lo vieron en su día, como una compensación a Colombia por la pérdida de Panamá, zona de valor estratégico único y por cuyo control los Estados Unidos, prescindiendo de todo disimulo, ocuparon militarmente la zona del canal. La compensación territorial a Colombia sería a costa del Perú, con la entrega de vastos territorios amazónicos y con una salida a la navegación fluvial del Amazonas, a través del Trapecio de Leticia.

El gobierno dictatorial de Leguía aceptará el tratado, impuesto como condición para su propia supervivencia, con la oposición de todo el país, para quien se trataba de un expolio y de la amputación del territorio nacional de una zona geográfica de enormes posibilidades futuras, en la que aparecerá pujante un nuevo competidor: la República de Colombia.

Tras la caída de Leguía, por la crisis del 29, el nuevo gobierno peruano - resignado con la pérdida de los territorios al norte del río Putumayo-

4 El Protocolo Salomón-Lozano o el Pacto de Límites con Colombia. Al Congreso Nacional. Lima, 1927, 91 p., 2 h., map. pleg. Archivo del Reino de Galicia, Biblioteca Iglesias Brage (en adelante, ARG, Bca. IB), 186. Las Casas, Gaspar de: Un Scandale Diplomatique. Le traité Salomon-Lozano. Paris, 1933, 155 p., 1 h., map. pleg. ARG, Bca. IB, 189. IB, 148 (1). Memorial apresentado pelos habitantes do territorio chamado Trapecio de Leticia à Liga das Naçoes, a raiz da chegada dos membros da Comissao. Territorio de Loreto, 15 de Julho de 1933 / (Assignados) J.E. Giles, Isidro Ruiz, Andrés Fonseca, Alberto Zuñiga Carlin (seguen mil e duzentas assignaturas). S.1., s.i., s.a., 1 h., con "Mapa do Norte do Perú com os limites do Tratado Salomão - Lozano. IB, 148 (1). Memorial de los pueblos de Loreto sobre el tratado Peru-Colombiano de 1922 / La Junta Patriotica de Loreto. Iquitos, 10 de Octubre de 1932. Iquitos (Perú), Imp. "El Oriente”, s.a., 1932, 26 p. (8 p. imp., 9-26 en blanco para recogida de firmas, con una carta manuscrita de Luis Mairala dirigida a Iglesias, firmada en Iquitos, el 4 de abril de 1933. Mairala fue Secretario de la Cámara de Comercio de Iquitos y prestó su apoyo, con gran entusiasmo, a la Expedición que estaba organizando Iglesias al Alto Amazonas. "[Tratado Salomón-Lozano]”. El Comercio, Lima (26 mayo 1934) reprodujo íntegramente el tratado. Tudela, Francisco: La Controversia Perú-Ecuatoriana. Lima, 1941, 48 p., map. pleg., 2 h. 
tras la ocupación del Trapecio por civiles del departamento de Loreto, centrará el conflicto en torno a este punto geográfico, que es la llave para abrir el paso a la navegación directa por el gran río Amazonas.

El conflicto se internacionalizará, al llevarlo Colombia ante la Sociedad de Naciones, quien creará una Comisión de Administración para intentar evitar el choque armado entre los dos vecinos en tanto se iniciaran las conversaciones. Esta Comisión estará integrada por un representante brasileño, un estadounidense y un español. Su labor se desarrollará en medio de dificultades producidas por los intereses enfrentados de los distintos países, hasta la firma del acuerdo entre los dos estados en litigio, en Río de Janeiro en 1934, con el triunfo de las tesis colombianas.

En este trabajo nos hemos detenido especialmente en la actuación del delegado español, el entonces Capitán de Aviación Francisco Iglesias Brage, tanto por la importancia y papel protagonista que tuvo dentro de la Comisión de Administración del Territorio, como por la mayor información que tenemos sobre él, puesto que la fuente principal que hemos manejado es su propio archivo personal, del que damos noticia más adelante.

\section{El Tratado Salomón-Lozano y sus consecuencias}

\section{El Tratado Salomón-Lozano y sus antecedentes históricos}

El Tratado Salomón-Lozano fue firmado en Lima, el 24 de marzo de 1922, entre el Ministro de Relaciones Exteriores de Perú, Alberto Salomón, y el Plenipotenciario de Colombia, Fabio Lozano T., y ratificado en Bogotá el 19 de marzo de 1928.

Por él, ambos gobiernos fijaron de común acuerdo una línea de frontera que pusiese término a su antiguo litigio territorial en el Oriente. Esa línea partía desde el punto en que el meridiano de la boca del río Cuhimbé, en el Putumayo, corta al río San Miguel o Sucumbios, sube por el mismo meridiano hasta la dicha boca del Cuhimbé; de allí, por el "thalweg" del río Putumayo hasta la confluencia del río Yaguas; sigue por una línea recta que desde esta confluencia va a la del río Atacury, en el Amazonas, y de allí, por el "thalweg" del río Amazonas hasta el límite entre Perú y Brasil, establecido en el tratado peruano-brasileño de 24 de octubre de $1851 .^{5}$

$5 \mathrm{IB}, 148$ (1). Ponto (O) de vista loretano sobre a questão de Leticia no Oriente peruano. Da colonia peruana ao povo de Amazonas. A Colonia peruana do Amazonas. Textos de Alberto Ulloa. Manáos, 8 de Fevereiro de 1933, 2. a ed. (1. a ed.: Manáos, 15 de Janeiro de 1933). S.1., ski., s.a., 1 h.., con map. 
Los antecedentes históricos, según Perú, se basaban en el siguiente razonamiento:

-El principio de los límites coloniales o "uti possidetis", que significa la continuidad del estado posesorio presente y futuro, reconocido por Colombia según el Tratado de Bogotá de 1811 y adoptado por los demás países hispanoamericanos como único medio de resolver sus litigios de fronteras, no fue tomado en cuenta en el Tratado Salomón-Lozano. Perú estuvo siempre en posesión legítima de los territorios cedidos a Colombia y que formaban parte de la antigua Comandancia del Maynas, organizándolos, administrándolos y fomentando sus intereses en la vasta zona comprendida entre el Caquetá y el Putumayo, con la creación de centros industriales como la Chorrera y el Encanto, mostrando siempre sus pobladores su voluntad de seguir perteneciendo a Perú.

-Por la aceptación del "uti possidetis" colonial quedaba reconocida la territorialidad de Maynas con sus límites naturales fijados por la real cédula de 15 de julio de 1802 . La validez de dicha real cédula y su efectividad práctica fue reconocida por la misma Colombia, por intermedio de Bolívar, que en su célebre carta de 1822 al general Santander le manifestaba que Perú se encontraba en posesión de esos territorios según una real orden muy moderna, y por los plenipotenciarios colombianos Galindo y Tanco en las conferencias de 1894.

-Perú continuó en posesión de sus provincias de Maynas (actuales departamentos de Loreto y San Martín) desde que nació como estado independiente, y esta posesión reúne las condiciones exigidas para la prescripción adquisitiva: justo título, largo transcurso de tiempo y falta de reclamación suficiente.

-Esta posesión se conservó sobre todos los territorios de la región amazónica, no obstante las contingencias de la guerra peruano-colombiana, y a través del Convenio de Girón y el Tratado de Guayaquil de 1829, reconociéndose ambos países sus respectivos territorios y dejando sólo pendiente la delimitación en la cual podrían hacerse mutuas concesiones, no de provincias, sino de las pequeñas porciones que fuesen necesarias para regularizar la línea fronteriza. Las acciones de armas en el Caquetá, la Unión y la Reserva consolidaron los derechos de Perú, defendidos siempre por la diplomacia y la sangre peruana. La Santa Sede erige el obispado de Chachapoyas en la bula "Ex Sublimi Petri Specula", de 2 de julio de 1843, con los territorios de la antigua Comandancia. Y con arreglo al artículo séptimo del tratado con Brasil, aceptando el principio del "uti possidetis", que- 
dó establecida como frontera "la población de Tabatinga y de ésta para el norte la línea recta que va a encontrar de frente al río Yapurá en su confluencia con el Apaporis y de Tabatinga por el Sur el río Yavary". ${ }^{6}$

Los antecedentes históricos, según Colombia, pueden resumirse en el discurso que el Sr. Santos, representante de Colombia, pronunció en la sesión del 21 de febrero de 1933 de la Sociedad de Naciones, en presencia de los miembros del Consejo y del Presidente, que venía a decir así:

- Se afirmaba que Perú había cedido territorios inmensos que le pertenecían desde hacía siglos. Antes de la independencia, toda la América española formaba un conjunto, los límites de los estados eran límites vagos, y constituían simplemente arreglos administrativos hechos por España según las necesidades de la Administración. Después de la independencia, todos los Estados se encontraron con una complicación enorme de títulos, pues ciertas disposiciones de la Corona española eran naturalmente contradictorias. Así, todos los estados americanos presentaron reivindicaciones territoriales muy grandes, cada uno de ellos tenía títulos sobre regiones idénticas que era preciso partir.?

-En la cuestión de los límites entre Perú y Colombia, ésta exigía la frontera del Amazonas entera, en tanto que Perú exigía una frontera al norte, casi en los alrededores de la cordillera. El asunto se solucionó con cordura y justicia, teniendo en cuenta los verdaderos intereses de América. En virtud del tratado de 1922, se dio a Colombia una pequeña parte sobre el Amazonas, a fin de que este país tuviera títulos para navegar por este río.

- Continuaba el Sr. Santos diciendo que en Perú se levantaban clamores extraordinarios hablando de su nacionalismo y sus derechos sobre su territorio, pero que él preguntaría cuáles eran los trabajos que Perú emprendió en la zona que reivindica, qué ha hecho en todo ese territorio que pretende ser peruano: no hay ni una ciudad, ni una carretera, ni una iglesia, ni una escuela, ni una sola obra de civilización y de progreso. No hay nada en toda esta región, de la que se quiere hacer ahora el corazón del Perú. Sólo existe una prueba trágica de la ocupación peruana de la región del Putumayo. Cuando el caucho era considerado como el oro de América, hace 20 o 25 años, las casas peruanas de Iquitos quisieron explotar el caucho de forma intensiva, y se comenzó a hacerlo en todo el Putumayo, uti-

6 Memorial de los pueblos de Loreto sobre el tratado Peru-Colombiano de 1922, citado.

7 Sobre esta cuestión confrontar Sixirei Paredes, Carlos: "Problemas territoriais das repúblicas americanas despois da independencia", en Iglesias Brage e América. A recuperación dun personaxe para a Historia de Galicia [Catálogo de exposición]. S.1., Xunta de Galicia, 1992, págs. 64-75. 
lizando a los indígenas, que fueron tan maltratados que Inglaterra procedió a enviar una comisión de encuesta, presidida por sir Roger Casement. Esta comisión publicó un Libro Rojo que motivó un gran escándalo en América porque demostraba que se había acudido a procedimientos de esclavitud de tal crueldad y salvajismo que la humanidad entera debía protestar contra estos actos. ${ }^{8}$

\section{Análisis del Tratado Salomón-Lozano}

\section{Análisis del Tratado en relación a Perú}

La línea fundamental del tratado era el río Putumayo, en el cual los dos países se reconocían libertad de tránsito y derecho de navegación. Lógicamente, esta línea debía continuar hasta el punto en que el río Putumayo, saliendo del territorio de Perú, ingresa en el de Brasil, y por tal río debía haber continuado también la navegación colombiana, hasta la desembocadura del Putumayo en el Amazonas.

Sin embargo, no fue así, y se aceptó la absurda quiebra de la línea del Putumayo, que se detuvo en su confluencia con el río Yaguas, bajando por una línea recta que iba desde esta confluencia hasta el río Atacuary, en el Amazonas, y ésto dio a Colombia el dominio ribereño sobre el Amazonas, desde ese último punto hasta el límite de la antigua frontera Perú-Brasil. De esta manera, la navegación y el supuesto tráfico comercial colombiano, en vez de seguir la línea natural del Putumayo hasta el Amazonas brasileño, tenía el derecho impracticable de convertirse en tránsito y tráfico terrestre y de bajar por un corredor territorial inadaptado en medio de la floresta hasta la margen del Amazonas, en uno de cuyos puntos se encontraba la población peruana de Leticia.

Para juzgar de la importancia y gravedad de la cesión a Colombia de la zona comprendida entre la confluencia del Yaguas, el Putumayo, la confluencia del Atacuary y el Amazonas, basta considerar que Colombia no había reclamado, en su largo proceso de controversia, ningún derecho histórico ni ninguna exigencia económica sobre la zona territorial indicada, y que su pretensión máxima había sido salir a la bacía del Amazonas, lo

8 IB, 145 (2). Société des Nations. [Actas de las Sesiones del Consejo de la] Soisante et onzième session (extraordinaire) du conseil. C/71 e Session / P.V. 1(1). 
que le daba una opción para participar en el porvenir, en la concurrencia comercial y política que podía tener por eje el gran río. El tratado afectaba profundamente la vida del oriente peruano. No sólo era un nuevo concurrente en la navegación y en el tráfico comercial, sino que era la Colombia interpuesta entre Perú y Brasil, aguas abajo del Amazonas, es decir, en situación de dificultar, como de hecho sucedió, o de cerrar eventualmente el libre tránsito peruano hacia, o procedente del Atlántico.

Durante casi un siglo, el condominio de Brasil y de Perú en la gran arteria fluvial no había originado ninguna dificultad cuyo recuerdo deba retenerse. Era, sin duda, absurdo e imprudente introducir un nuevo condominio, darle sobre el río una posición privilegiada. El estorbo y el peligro para el oriente eran un estorbo y un peligro para Perú, consolidado en su región amazónica, no sólo por razones elementales de cohesión nacional, política y afectiva, sino por el interés en conservar la posición que la naturaleza y la historia le habían dado en el corazón del continente. ${ }^{9}$

La vasta extensión territorial entregada por el Perú tenía un área superior a diez millones de hectáreas, colonizada desde hacía más de un siglo, civil, militar y eclesiásticamente, ${ }^{10}$ registrando allí más de veinte mil habitantes, legítimamente peruanos, y distribuidos en las poblaciones de Leticia, Victoria, Loreto, Santa Sofía, Loreto Yaco, Brea, Sancudo, Atacuary, São Nicolás, Supe, Calla Calla, Sobra, Erayos, Unanimayos, Iberia, Chorrera, Encanto, Oriente, Occidente, Sur, Entre-Ríos, Sábana, Retiro, Emerayos y otros, además de los pobladores de los ríos Hamaca-Yaco, Meta, LoretoYaco, Cothué, Yaguas y tantos otros que sería largo enumerar.

Con ocasión de la toma de Leticia, el 1 de septiembre de 1932, no excedía de 50 el número de colombianos allí existentes, todos empleados públicos, para administrar a los colonos peruanos, cedidos por el texto del Tratado Salomón-Lozano. ${ }^{11}$

Aparte del absurdo político y geográfico ya mencionado, según los habitantes de Loreto, ${ }^{12}$ existían estas otras circunstancias a tomar en cuenta:

a) El trapecio amazónico (Leticia) no fue nunca un territorio disputado, ni de penetración colombiana, no había (hasta la fecha de este manifiesto, en 1933) intereses económicos ni poblaciones colombianas.

9 Ponto $(O)$ de vista loretano, citado.

10 Contreras, Francisco: Reseña histórica de las misiones franciscanas en el Perú. Valencia, Tip. Moderna, A.C. de Miguel Gimeno, 1926, 63 p., grab., lám., map., 2. ${ }^{\text {a ed. aum. }}$

11 Ponto $(O)$ de vista loretano, citado.

12 Ídem. 
b) La totalidad de la población, que era peruana, no fue consultada de forma alguna, como establecen los principios y las prácticas del Derecho Internacional, para el cambio de nacionalidad.

c) Para ocupar la margen amazónica que le adjudicó el Tratado, Colombia necesitaba llegar a ella a través de Brasil, descendiendo el Putumayo hasta su confluencia con el Amazonas, y remontando luego éste hasta Leticia.

d) No había posibilidad alguna de que la margen amazónica sirviera a Colombia para comunicarse ni para el tráfico con este río ni con el Atlántico, pues sus comunicaciones y su tráfico, así como su comercio, cuando llegase a existir apreciablemente en esas regiones, tendría que seguir la vía indicada del Putumayo hasta Brasil.

e) Los productores de la zona del trapecio amazónico cedida a Colombia no podían comerciar con este país, sino con Perú, ni tenían en el primero mercados accesibles de venta de sus productos ni de adquisición de sus elementos.

f) Hasta veinticinco días después de ocurrido el suceso de Leticia, la autoridad de Colombia no llegó a manifestarse en esa región.

\section{Análisis del Tratado en relación a Colombia}

Por la segunda parte del artículo primero del Tratado de 1922, Colombia declara que cede a Perú el territorio comprendido entre el río Putumayo y el Sucumbios o San Miguel, conocido comúnmente con la denominación de triángulo de San Miguel, que Ecuador reconoció a Colombia en virtud del Tratado de 15 de julio de 1916. Según el internacionalista venezolano Jacinto López, este tratado carece de seriedad fraternal.

Este territorio, sin área determinada, deshabitado, agreste y salvaje, hállase situado en los confines del Alto Putumayo, con diminuta y ridícula dimensión, lejos, muy lejos, de los dominios de Perú, prácticamente enclavado entre Ecuador - que posee la boca del Sucumbios y una parte de la margen derecha del Putumayo donde tiene sus guarniciones militaresy Colombia, que posee la margen izquierda de este último río. Las dificultades de acceso de Perú al indicado territorio no podían pasar desapercibidas a las comisiones demarcadoras, que trataron de salvar las apariencias 
IGLESIAS BRAGE EN LETICIA

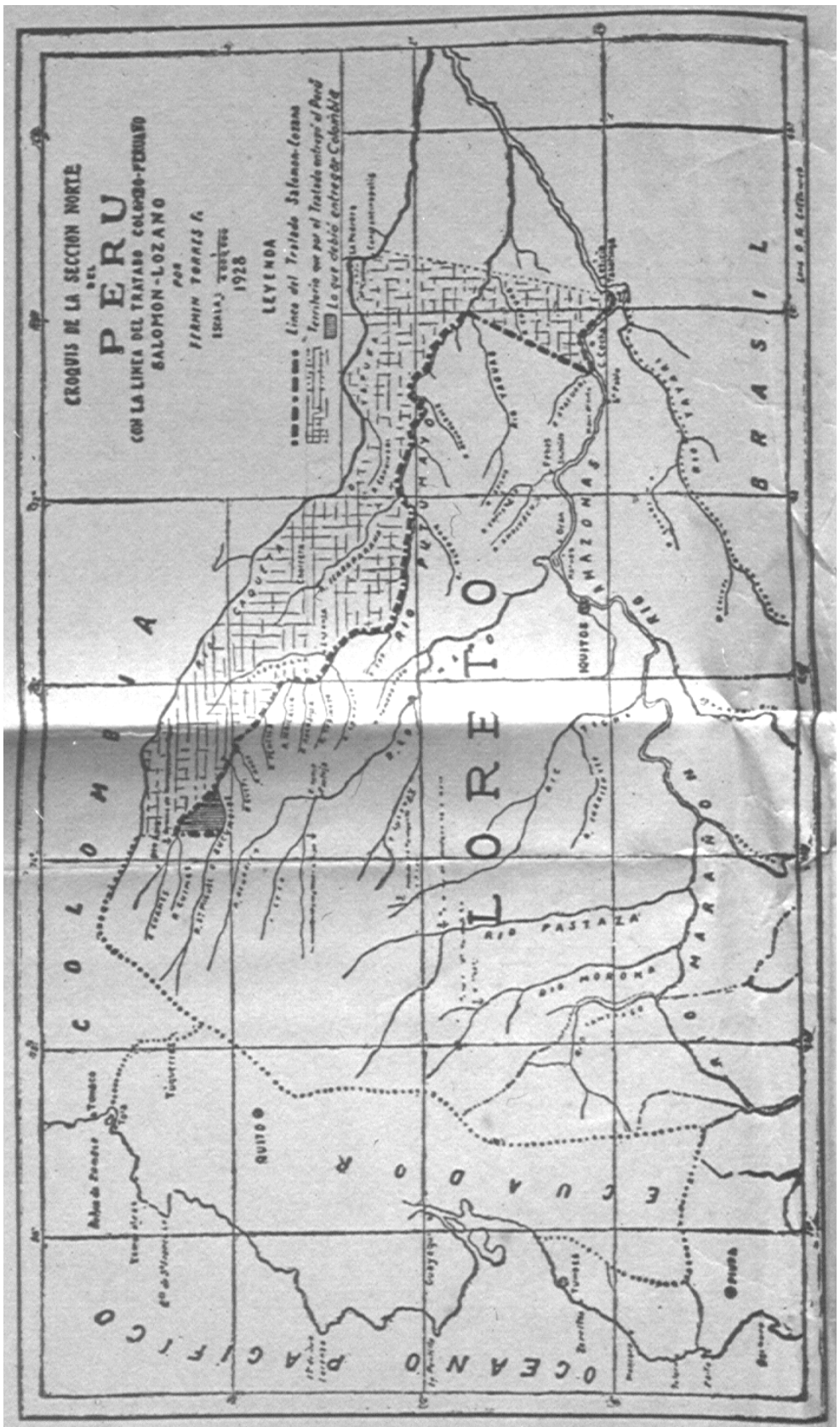

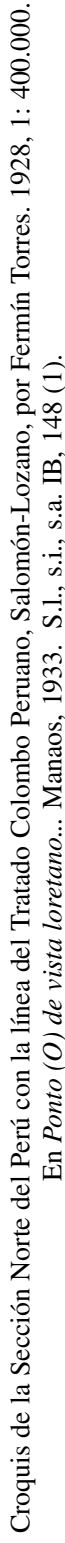


en el papel porque de lo contrario hubiera quedado ejecutoriedada la inaplicabilidad del Tratado. ${ }^{13}$

Es inevitable la comparación que los contemporáneos realizan del caso con el de Panamá al conseguir su independencia. En esta república, antes territorio colombiano, los Estados Unidos fomentaron un movimiento separatista, sin verdadero enraizamiento histórico, ni político, ni sentimental; lo apoyaron con la fuerza de su marina de guerra; notificaron al mundo que lo consideraban como un hecho irrevocable, y a Colombia que no consentirían la actuación militar contra los insurrectos..$^{14}$ A pesar de constituir un atentado contra la soberanía colombiana y contra el Derecho Internacional, producto de una política deliberada e inescrupulosa, de la que los Estados Unidos se jactaron, el hecho tuvo suficiente fuerza, por sí mismo, para determinar una situación internacional que Colombia acabó por aceptar. Esta aceptación no redime ni jurídica ni moralmente al atentado norteamericano, pero revela cómo un acto de naturaleza injustificable puede crear una situación que tiene que ser considerada y que genera un nuevo estado jurídico. ${ }^{15}$

Además, Colombia, a pesar de que Panamá había consolidado ya su independencia, por compensación y otras cláusulas, determinadas en los artículos $1 .^{\circ}, 2 .^{\circ}$ y $3 .^{\circ}$ de su tratado con los Estados Unidos de América, en marzo de 1922, recibió de este país 25.000.000 de dólares y el franco y libre paso por el Canal de Panamá de sus naves, tropas y material de guerra sin pagar derecho alguno. ${ }^{16}$

\section{El Tratado Salomón-Lozano y la actuación del Presidente Leguía}

El Protocolo suscrito en Lima el 24 de marzo de 1922 por el Ministro de Relaciones Exteriores del Perú, doctor Alberto Salomón, y el Pleni-

13 IB, 148/1. Ponto (O) de vista Peruano no conflicto Perú-Colombiano sobre o caso de Leticia. Terceira Explicação. A Colonia Peruana do Amazonas. Manáos, 10 de março de 1933. S.1., s.i., s.a., 2 h., con mapa. Memorial de los pueblos de Loreto sobre el tratado Perú-Colombiano de 1922, citado.

14 Para una perspectiva de las relaciones EEUU-Panamá, véase Pizzurno-Gelos, Patricia: Harmodio Arias Madrid y las relaciones internacionales. Panamá, 1992. Pizzurno Gelos, Patricia: Antecedentes, hechos y consecuencias de la Guerra de los Mil Días en el Istmo de Panamá. Panamá, Formato 16 / GECU, Universidad de Panamá, 1990, 233 págs.

15 Ponto $(O)$ de vista loretano, citado.

16 Ponto $(O)$ de vista Peruano no conflicto Perú-Colombiano sobre o caso de Leticia. Terceira Explicação, citado. 
potenciario de Colombia, doctor Fabio Lozano, se mantuvo en secreto hasta su discusión en el año 1927. No obstante interesar a todo el país, se prescindió de la intervención de los principales organismos del Estado, llegándose al extremo de desestimar los trámites más elementales: no se sometió al voto consultivo del Consejo de Ministros, como lo reveló el Presidente del Gabinete de esa época, don Germán Leguía Martínez, y se omitieron los informes del Archivo de Límites, del Asesor Jurídico del Ministerio de Relaciones Exteriores, y de la Sociedad Geográfica.

El Gobierno, presionando continuamente a la comisión diplomática del Congreso para que dictaminase, hizo todo para imponer la aprobación del Protocolo y en sus mensajes desde el año 1922 se anticipó a la resolución del Parlamento. Su plan de desmembración del territorio nacional encontró fácilmente, en el círculo de sus adictos incondicionales, poderosos auxiliares de este derrotismo diplomático. El diario La Prensa, confiscado por el Gobierno y órgano del oficialismo, fue dirigido por el ciudadano colombiano Guillermo Forero, quien interpretaba la política interna e internacional de Perú en el sentido de las conveniencias del régimen imperante. La prensa del resto del país estaba subvencionada y por consiguiente la prensa libre tuvo que desaparecer por obra de la dictadura. El gobierno personal y de fuerza contra las leyes y la opinión pública añoraba una gran victoria diplomática aún con desmedro de la patria. La dictadura de los 11 años sojuzgó todas las libertades públicas consumando su obra destructora con la organización de una burocracia envanecida por las prebendas e inspirada tan sólo por la consigna del gobernante a quien debía sus favores.

A Loreto envió el Gobierno a las personas de más confianza para ocupar los diferentes cargos en la administración departamental, no para auscultar los sentimientos de la población, sino para ahogarlos. La actitud del prefecto de Loreto, encaminada a desprestigiar a todos los que no pensaban conforme a los deseos del jefe del estado, se comprueba en su comportamiento con el senador Arana, quien en repetidas ocasiones invocó su patriotismo insinuándole que informara al gobierno acerca de la inconveniencia e impopularidad del mencionado pacto. El prefecto de Loreto envió una carta al Presidente de la República manifestando que "este señor se ha dedicado a llevar a cabo una serie de intrigas contra mí porque no le dejo hacer lo que le place aquí, porque siempre ha contrarrestado su campaña contra el Gobierno, por el asunto Protocolo Salomón-Lozano". ${ }^{17}$

17 Cartas encontradas en el archivo particular del señor Leguía, publicadas en el diario El Pueblo de Lima, 13 de enero de 1931. Confróntese el Memorial de los pueblos de Loreto, págs. 1-2. 
Contrasta esta campaña de persecución del gobierno contra los defensores de la integridad territorial con la protección dispensada a los propagandistas del tratado, entre ellos un ex empleado de Marina, D. J. Constnate Hoyle, quien redactó un informe, acompañado de un plano, recomendando la aprobación de este pacto lesivo, que hizo circular entre todos los representantes del Congreso. ${ }^{18}$

Se obstruyó todo esfuerzo que se opusiese al Tratado, mediante violencias y amenazas a los pocos peruanos patriotas que trataron de impedir la desmembración del territorio nacional. La policía secuestró en la Imprenta "La Tradición" la edición de los folletos del senador por Loreto sobre el Protocolo Salomón-Lozano, y se prohibió su circulación, ejerciendo una estricta vigilancia sobre su autor. Esta actitud, que afectaba a los fueros del Parlamento y a la libertad de expresión, motivó las protestas consiguientes en el Senado. ${ }^{19}$

No obstante, el congreso regional del norte, en la legislatura de 1927, formuló su protesta contra el Tratado, considerando la situación jurídica de Perú sobre la zona que entonces se pretendía ceder, la obra colonizadora ya realizada por los habitantes de la región amazónica, la extensión del territorio objeto de la cesión - mayor que Portugal—y el peligro del condominio de Colombia en el Amazonas.

Dicho congreso de Tumbes, el 23 de junio, tuvo una sesión secreta, en la que los diputados regionales por Loreto de San Martín decían que según nota editorial de La Prensa, de Lima, de 23 de mayo, el Tratado SalomónLozano, firmado el 24 de marzo de 1922 y ratificado por el Parlamento colombiano, había de serlo en el Congreso nacional peruano; que algunas cláusulas del Tratado se habían publicado por la prensa brasileña, que se reprodujeron en los diarios de Iquitos, originando una acalorada polémica sobre su veracidad, que fue confirmada por el cónsul de Brasil, Sr. Felippe de Mello; y que para que se pasase a las comisiones diplomáticas de las cámaras nacionales, con el acuerdo del congreso nacional, hacían la siguiente exposición:

1. ${ }^{\circ}$ El carácter histórico de la soberanía peruana sobre los territorios objeto del tratado nace de la época de la colonización, en que la región de Maynas, después de haber pertenecido por seis años al Nuevo Reino de Granada, fundado el 29 de abril de 1717, extinguido éste, pasó al Virreinato

18 El Eco, 30 de abril de 1927. Confróntese el Memorial de los pueblos de Loreto, págs. 1-2. págs. 1-2.

19 Diario de los Debates, 1927, pág. 476. Confróntese el Memorial de los pueblos de Loreto, 
del Perú y Audiencia de Quito. Posteriormente, en agosto de 1739, la gran cédula expedida en San Ildefonso restableció nuevamente el Virreinato de Santa Fe, estableciéndose el 2 de septiembre de 1772 las misiones de Maynas, hasta que, en vista de los informes de don Francisco Requena, gobernador y comandante general de las mencionadas Misiones, la opinión de los fiscales de la Corona delante del Consejo de Indias, a las consultas de 26 de marzo y de 7 de diciembre de 1801, y el parecer del Consejo sobre el modo de proceder el gobierno provisional de la provincia de Maynas, elevado por la Audiencia de Quito, Su Majestad el Rey decretó con data de 15 de julio de 1802:

\footnotetext{
"Que se tenga por desligado del Virreinato de Santa Fe y de la Provincia de Quito, y aumentada con eso el Virreinato del Perú, el Gobierno y la Comandancia General de Maynas, con los pueblos del gobierno de Papallacta, por estar todos ellos en las márgenes del Napo o en sus inmediaciones, extendiéndose aquella Comandancia General no solo por el río Marañón abajo hasta las fronteras de las colonias portuguesas, sino también por todos los demás ríos que llevan sus aguas al mismo Marañón por sus márgenes septentrionales, como son: Morona, Pastaza, Ucayali, Napo, Javary, Putumayo, Jupurá y otros menos considerables hasta la altura en que estos mismos ríos, por sus saltos y correnteras inaccesibles, dejen de ser navegables".
}

Cumplido este mandato por los virreyes del Perú y de Santa Fe, respectivamente, se estableció en 1810 el principio del "uti possidetis" americano que todos conocemos.

Nuestra independencia en nada alteró lo establecido, y el Perú continuó y continúa ejerciendo su soberanía, manteniendo autoridades, sustentando guarniciones militares, establecimiento de misiones, instalación de trabajos industriales, navegación bajo nuestro pabellón con embarcaciones de vapor, torres de telegrafía sin hilo y escuelas.

2. ${ }^{\circ}$ La colonización de esas regiones se llevó a cabo por los hijos y vecinos de los departamentos de San Martín y Amazonas, los que, con el sacrificio de sus vidas y exponiendo sus capitales, en medio de los infinitos peligros de la vida en las selvas, han vuelto efectivos los derechos de Perú hasta donde se encuentran los destacamentos actuales de las guarniciones militares, cuya exacta posesión puede consultarse en los mapas del Estado Mayor General del Ejército. Una de las casas peruanas, "The Peruvian Amazon Company", hizo y continúa haciendo una valiosa obra de civilización en la región de los ríos Putumayo y afluentes, reintegrando a la nacionalidad más de 20.000 indios que hoy son civilizados y llevan un apreciable contingente de brazos y energías al progreso de la montaña. 
3. El Tratado Salomón-Lozano contempla la cesión a la República de Colombia de un territorio mayor que el de Portugal, pues llega a cien mil kilómetros cuadrados, incluyendo las zonas más ricas en productos gomíferos como "borracha, balata, chicle, etc.", que son también las tierras mejores del departamento de Loreto para la agricultura, constituyendo su despensa, por no inundarse y favorecer así una constante producción agrícola, que contrapesa la falta de ella en otras tierras bajas o inundables. Toda la actividad industrial y todo el comercio de Loreto se basa en la producción del sector señalado para formar parte del territorio colombiano, y sucede que después de los acuerdos con Brasil y Bolivia, por los cuales pasaron a formar parte de aquellas repúblicas zonas inmensamente ricas, hemos quedado con el único tesoro que valoriza nuestra región oriental y que, por doloroso contraste, es el objeto del tratado de referencia.

4. ${ }^{\circ}$ Si nuestra frontera con el Brasil, Leticia, pasase a manos extranjeras, y junto con ella Pebas y otros poblados y con ellos las industrias establecidas, como son: haciendas de ganado vacuno, ingenios de azúcar, serrerías, etc., valuados en varios millones de soles, habremos asestado un golpe de muerte a la vida agonizante de Iquitos y de toda la región, pobre ya, con la vecindad de Colombia, que se expansionaría por el Amazonas, y llegaría a tal estado de postración que es fácil prever sus fatales consecuencias.

Este alegato iba firmado por João Vergara, diputado regional por el Bajo Amazonas, Oswaldo Corpacho, diputado regional por el Ucayali, B. Antonio Acosta, diputado regional por Jurimaguas (Alto Amazonas) y Paulo del Aguila, diputado regional por Moyobamba. ${ }^{20}$

La gente de Loreto también protestó, solicitando que se tuviese en cuenta sus deseos, pidiendo el nombramiento de una comisión parlamentaria que visitase la región comprendida en el Protocolo y que se consultase previamente la voluntad de los "regnícolas".

La respuesta del Jefe del Estado es la prueba más expresiva de que para el régimen de fuerza imperante no valía nada la opinión pública. En un telegrama de contestación a una de las peticiones de que no se ratificase el tratado, Leguía le decía al prefecto coronel Molina Derteano lo siguiente:

"Prefecto Coronel Molina Derteano -Iquitos-. Solo es excusable la actitud de los que me dirigen el radiograma relacionado con el Protocolo Salomón-Lozano, porque ignoran las verdaderas causas del Tratado con Colombia y no ven en él sino el daño

20 Ponto $(O)$ de vista Peruano no conflicto Perú-Colombiano sobre o caso de Leticia. Terceira Explicação, citado. 
de intereses personales o de carácter lugareño. Esa ignorancia sin embargo no excusa a los servidores públicos que con olvido de sus deberes y de la lealtad que deben al Régimen se unen a los que protestan de sus actos o pretenden enmendarlos. Mándeme Vd. una lista completa de todos los que se hallen en esa condición y haga usted saber de una manera general que, por la Constitución, el Presidente de la República tiene la gestión de los asuntos internacionales y es capaz para juzgar la conveniencia nacional de los tratados. Haga saber que no se permitirá ningún acto que se traduzca en obstrucción al cumplimiento del Tratado con Colombia. Recuérdeles Usted, que cuando se dio el fallo de Washington, también el Perú en masa, y hasta las damas de Lima, asumieron una actitud idéntica a la de los loretanos hoy, y que si el Gobierno entonces hubiera hecho lo que se le pidió del pobre Perú, no quedaría ahora sino el recuerdo de un pueblo torpe, degenerado e indigno. Con igual visión se va a aprobar el pacto con Colombia y su cumplimiento se traducirá en grandes bienes para el País. Ajuste Usted sus procedimientos a las deducciones que le sugiera el tenor de este radiograma. Saludos. Presidente Leguía". ${ }^{21}$

De acuerdo con la orden recibida, el prefecto Molina mandó la lista de los firmantes que le había sido solicitada, en la que figuraban algunos funcionarios públicos que, por la actitud que habían asumido, fueron inmediatamente destituidos de sus cargos. ${ }^{22}$

\section{El cumplimiento del Tratado Salomón-Lozano}

Perú hizo entrega a Colombia de los territorios que se especificaban en el tratado mediante una comisión, presidida por el prefecto de Loreto, que se constituyó en Leticia, mediante un acta final de 2 de agosto de 1930, suscrita en Iquitos por los señores Molina Derteano y Acevedo, jefe de la comisión colombiana, reduciéndose ésta a declarar la cesión territorial a favor de Perú de los territorios que le correspondía entregar a Colombia, sin un acto material que lo consolidase. La entrega se hizo en virtud de una orden telegráfica, perfectamente anticonstitucional, del dictador Leguía al mencionado prefecto. ${ }^{23}$

Esta solución a la disputa fronteriza con Colombia, que le permitía contar con un puerto fluvial navegable en la cuenca del Amazonas, Leticia,

21 Publicado en El Eco de Iquitos, los días 10, 12 y 16 de diciembre de 1927. Confróntese el Memorial de los pueblos de Loreto, pág. 4, donde se incluye el texto en castellano y Ponto $(O)$ de vista Peruano no conflicto Perú-Colombiano sobre o caso de Leticia. Terceira Explicação, pág. 3, con el texto en portugués.

22 Ponto $(O)$ de vista Peruano no conflicto Perú-Colombiano sobre o caso de Leticia. Terceira Explicação, pág. 3.

23 Memorial de los pueblos de Loreto, pág. 8. 
aún a costa de penetrar profundamente en terrenos afirmados como peruanos, no fue la única que abordó el populista y poco escrupuloso Leguía. También resolvió el contencioso con Chile sobre las provincias fronterizas de Tacna y Arica, que debía haberse sometido a un plebiscito, como estipulaba el tratado de 1883, finalizada la guerra del Pacífico. Tras el intento infructuoso patrocinado por los norteamericanos de llevarlo adelante en 1926, Leguía negoció un tratado, firmado en 1929, que permitía el retorno de Tacna al Perú, pero admitió la pérdida definitiva de Arica. Como el pacto era razonable, las tensiones entre los dos países se apaciguaron gradualmente..$^{24}$

\section{Nacionalismo, autocracia y delimitación de fronteras}

La crisis de 1929 acabó con el gobierno de Leguía y sus manejos financieros, aunque el factor último fuera la insurrección del joven coronel Luis Sánchez Cerro el 22 de agosto de 1930, que lo detuvo y encarceló. Durante su gobierno se habían acentuado algunos males endémicos del país, como el caciquismo provinciano, el fraude electoral y la corrupción. Una junta provisional dio paso a nuevas elecciones y la campaña de 1931 se convirtió en una contienda entre Sánchez Cerro, con un partido nuevo, la Unión Revolucionaria, de tintes fascistas, y Haya de la Torre, propulsor del APRA, una suerte de radicalismo revolucionario antiyanki que evolucionaría con el tiempo para adaptarse a la situación peruana y no enfrentarse directamente con los EEUU y el gran capital. Pero Sánchez Cerro ganó las elecciones, encarceló a su rival, y propugnó un gobierno populista y nacionalistas, intentando también aplacar a los elementos que habían apoyado al APRA, impulsando algunas mejoras sociales. En esta línea, tomaría partido por un grupo de civilistas que capturó el puerto de Leticia en 1932, y amenazaba con la guerra a Colombia. El gobierno peruano no sólo desafió a la Liga de las Naciones en este problema, sino que envió el Grau, y dos submarinos remontando el Amazonas, para defender sus "derechos". Pero el 30 de abril de 1933 Sánchez Cerro sería asesinado por un aprista.

24 Fagg, John: Historia General de Latinoamérica. Madrid, 1970, pág. 929. Morales Padrón, F.: Manual de Historia Universal. Tomo VI. Historia General de América. Madrid, 1962, págs. 513515, correspondientes al epígrafe "El Oncenio de Leguía". 
El Congreso eligió como Presidente interino, con la aprobación del estamento militar, al general Oscar Benavides, perteneciente a la oligarquía criolla, que se concentró en apaciguar al APRA y a sus potenciales seguidores llevando adelante una serie de reformas sociales, y en el curso de las elecciones de 1936 prolongó su mandato con la ayuda del ejército y las clases pudientes. Entre la suave autocracia y las parciales reformas de Sánchez Cerro y de Benavides, la oligarquía pasó el peligroso escollo de la crisis y supo hacerse con el control de la situación, y en 1939 fue elegido Manuel Prado Ugarteche, cuyos métodos se asemejaron bastante a los de los dictadores del Eje, pero cooperó fielmente, sin embargo, con los EEUU, lo que le proporcionó una inapreciable ayuda en la disputa fronteriza con Ecuador. Ésta se arrastraba desde el Tratado de Pando-Novoa de 1832, y la intransigencia en los respectivos planteamientos llevaría a un enfrentamiento armado, con la ocupación de la provincia

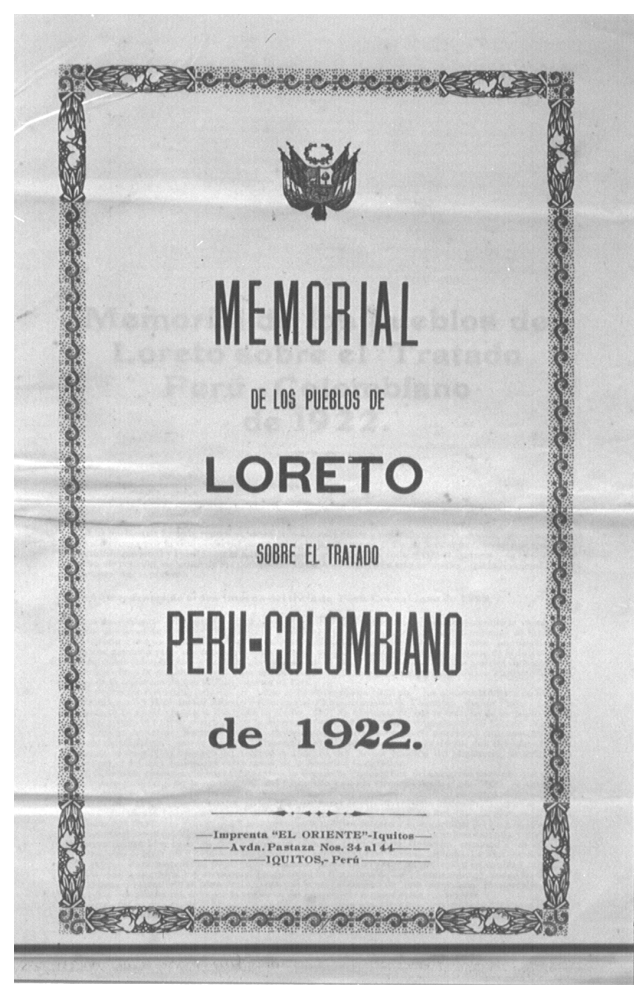

Portada del Memorial de los pueblos de Loreto... Iquitos (Perú), Imprenta "El Oriente”, 1932. IB, 148 (1). de El Oro por parte de Perú, pasando a estudiarse el asunto en la III Conferencia de Cancilleres de América, celebrada en Río de Janeiro, y concluyó con un beneficioso "protocolo de Paz, Amistad y Límites", el 29 de enero de $1942 . .^{25}$

Es en este contexto en el que debemos situar la crisis de Leticia y la intervención de la Sociedad de Naciones, así como la presencia en el "Trapecio" de nuestro protagonista, Francisco Iglesias Brage.

25 Fagg, Historia General de Latinoamérica, págs. 930-932. Morales Padrón, Historia General de América, págs. 524-526 correspondientes al epígrafe "La cuestión peruanoecuatoriana". 


\section{Iglesias Brage y la Comisión de Administración del territorio de Leticia}

\section{La Comisión de Administración del territorio de Leticia}

El día 19 de junio de 1933, a bordo del vapor colombiano "Mosquera", en el puerto de Tefé, Brasil, quedó constituida la Comisión de Administración del territorio de Leticia, con arreglo al acuerdo de 25 de mayo, y formada por Arthur W. Brown, Coronel del Ejército de los Estados Unidos de América del Norte, Alberto de Lemos Basto, Capitán de Fragata de la Marina de los Estados Unidos del Brasil, Francisco Yglesias Brage, ${ }^{26}$ Capitán de Aviación de la República Española y Armando Mencía, del Secretariado General de la Sociedad de Naciones. Los tres primeros como Comisarios, y el último como Secretario General. ${ }^{27}$ Pero ¿quién era este capitán de aviación español a quien se enviaba a una misión tan delicada? Veamos lo que decían de él a su llegada.

\section{Francisco Iglesias Brage ${ }^{28}$}

Nació en Ferrol (A Coruña), el 21 de mayo de 1900. Ingresó en la Academia de Ingenieros Militares en el año de 1918, de la cual salió con el grado de teniente en 1923. Fue destinado a Marruecos, a la zona occidental, en la que permaneció durante dos años, tomando parte en las operaciones

26 Iglesias aparece durante su actuación en Leticia escrito con Y griega: Yglesias.

27 IB, 146 (1). Comisión de Administración del Territorio. Actas de las sesiones de los días 19 a 24 de junio de 1933 .

28 He aquí la bibliografía más significativa sobre la vida de Iglesias: Escrigas, Guillermo: Ferrol en la aviación. [Prólogo de Germán Castro Tomé]. Ferrol, 1998, 107 págs., 2 h., il. "Francisco Iglesias Brage". El Eco, Iquitos (Perú), IX, n. ${ }^{\circ}$ 2.581, 27 julio 1933. (Biografía). Iglesias Brage e América. A recuperación dun personaxe para a Historia de Galicia, Santiago de Compostela, Xunta de Galicia. Consellería de Cultura e Xuventude, 1992, 124 págs., especialmente el capítulo del Comisario de la Exposición, Martínez García, Luis: "A Exposición Iglesias Brage e América”, págs. 21-94. López Gómez, Pedro: "El Capitán Iglesias, un ferrolano en la historia de la aviación". La Voz de Galicia (I), martes, 27 de marzo de 1979, pág. 48 (y II), 28 de marzo de 1979, págs. 20-21. Llorca Freire, Guillermo: "Iglesias Brage, Francisco", en Gran Enciclopedia Gallega, tomo XVII, Gijón, 1974, págs. 206-207. Llorca Freire, Guillermo: Franciso Iglesias Brage: No centenario do seu nacemento (Proxecto e coordinación editorial: Ricardo Nores Castro), Ferrol, 2000. Se acompaña de un "ÁlbumRecuerdo del Viaje de los Aviadores Españoles" (La Habana, 1929) y la Memoria "Expedición Iglesias al Amazonas. Proyecto Definitivo / Francisco Iglesias Brage” (Madrid, 1932), 144 págs., además del videocasete "Francisco Iglesias Brage: No centenario do seu nacemento, editado polo concello de Ferrol". Llorca Freire, Guillermo: "Tres aviadores ferrolanos", en La Voz de Galicia, 22 junio 1988. Nores Castro, Ricardo: "Tres aviadores”, en Ferrol Diario, 21 de marzo de 1971. 
militares que se llevaron a cabo por entonces como teniente de zapadores. Asistió a la ocupación de Xauen y a la campaña de 1924. Regresó a España en diciembre de este año para ingresar en la aviación militar, haciendo el curso necesario para obtener el título de observador. Volvió a Marruecos en mayo de 1925, esta vez a la zona oriental (Melilla) y en ella desarrolló sus actividades hasta fines de 1926. Participó en las campañas de la toma de Alhucemas y en la ocupación de la zona este del Protectorado español, siendo promovido al cargo de capitán por méritos de esta etapa, desarrollada en su calidad de observador y piloto del Servicio de Aviación en el Grupo de Escuadrillas de Melilla y Grupo de Escuadrillas Mixto.

En septiembre de 1926 regresó otra vez a España a conseguir su título de piloto, y en los primeros meses de 1927 fue nombrado Inspector del Estado en la Fábrica de Aviones de

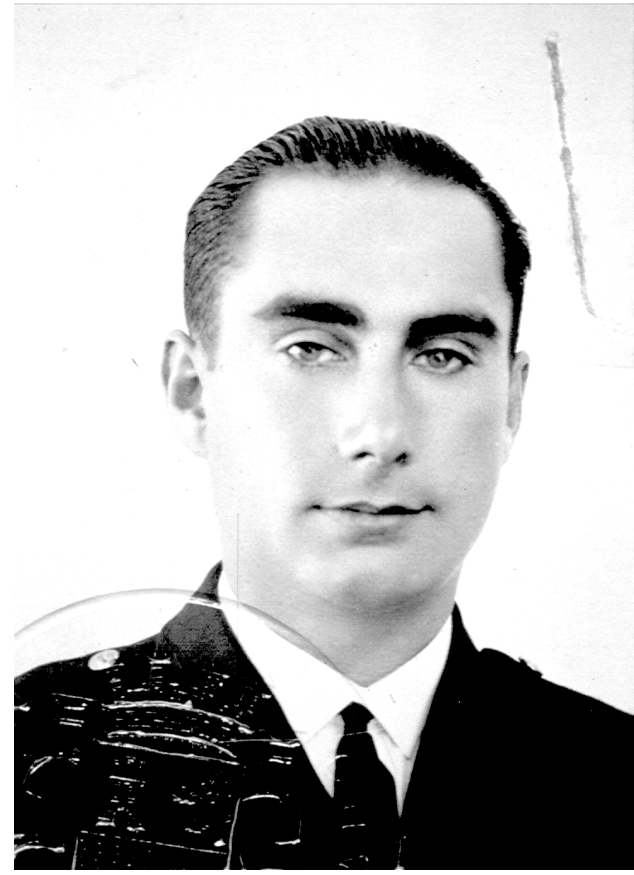

Retrato de Francisco Iglesias Brage a los 33 años. En su pasaporte diplomático. IB, 146 (13). Getafe (Madrid - Construcciones Aeronáuticas, S.A.) en la que desempeñó este cargo durante un año. Designado en unión del capitán Jiménez para intentar un vuelo de larga distancia, inspeccionó la construcción del avión "Jesús del Gran Poder", que se preparaba con aquel objeto. ${ }^{29}$ En octubre de dicho año realizó un vuelo de 14 horas sin escala, hacia la costa del Sáhara, tomando tierra por avería. En marzo de 1928 hizo otro de 30 horas de duración, sobre España, elevando al doble el récord nacional de permanencia en el aire, obteniendo en unión del capitán Jiménez el premio del Aéreo Club. En mayo del mismo año salió con dirección a la India inglesa recorriendo 5.000 kilómetros sin escala, en

29 Fernández, Carlos: “A Década Prodixiosa da aviación española (1920-1930), en Iglesias Brage e América. A recuperación dun personaxe para a Historia de Galicia, págs. 26-33. 
30 horas de vuelo, batiendo el récord nacional de distancia. Tomó tierra en las cercanías de Basora (Mesopotamia) — hoy Irak - por avería, permaneciendo sobre el desierto, en Irak y Palestina, durante tres meses, tras los que volvió a España en dos largos vuelos: Basora-Constantinopla en 14 horas, y Constantinopla-Barcelona en 13 horas.

En febrero de 1929 comenzó los preparativos del vuelo hacia América, también en el "Jesús del Gran Poder", ${ }^{30}$ con el que partió de Sevilla el 24 de marzo de este año, llegando a Bahía (Brasil) el día 26, después de atravesar el Atlántico en 44 horas de vuelo sin escala. Continuó el vuelo hacia Río de Janeiro-Montevideo-Buenos Aires-Santiago de Chile-Arica-Lima-PaitaPanamá-Managua-Guatemala y La Habana, cumplido con toda regularidad, con un recorrido total de 22.000 kilómetros. Parece que es en estos momentos cuando se despierta su interés por la Amazonía. ${ }^{31}$ Regresó a España en un crucero de guerra español desde la isla de Cuba.

Durante el viaje de Santiago de Chile a Lima fueron portadores, él y Jiménez, del Tratado de Tacna y Arica. El gobierno de Lima les otorgó la cruz peruana de Aviación.

En 1930 desempeñó el cargo de profesor técnico en la Escuela de Pilotos de Guadalajara, y en 1931 de Inspector en la de Albacete. A partir de abril de este año se incorporó a la Jefatura de Aviación en el Ministerio de la Guerra, en donde trabajó hasta 1931, cuando pasó a la situación de supernumerario, hasta 1932, en que habiendo aprobado el Gobierno de la República el proyecto de Expedición Científica a la Región Amazónica, preparado con la colaboración de los principales centros y entidades científicas de España, pasó al Ministerio de Instrucción Pública a fin de organizar dicha Expedición. ${ }^{32}$

30 Una selección de la bibliografía sobre el vuelo en su época y en su cincuentenario, en Álbum-recuerdo del viaje de los Aviadores Españoles Jiménez e Iglesias. Fiestas del 20 de Mayo. Habana, [Rafael Pegudo, Amador Vales, Fernando Lescano], 1929, 34 h., fot. Ero. "Gran Poder III", en La Voz de Galicia, 20 de marzo de 1979. García Pérez, A.: "Cincuenta aniversario del vuelo del 'Jesús del Gran Poder", en El País, 24 de marzo de 1979. "Homenaje ferrolano a Iglesias Brage en el cincuenta aniversario de su azaña", en La Voz de Galicia, 27 de marzo de 1979, pág. 47. "Mañana se cumplen 50 años del histórico vuelo del 'Jesús del Gran Poder. El ayuntamiento ferrolano hará una ofrenda floral ante el monumento conmemorativo'", en La Voz de Galicia, 25 de marzo de 1979, pág. 27. Nores Castro, R.: "Cincuenta aniversario del vuelo del 'Jesús del Gran Poder'”, en Ferrol Diario, 25 de marzo de 1979. R.L.: "El 'Jesús del Gran Poder' intentó batir el record mundial de distancia”, en El Ideal Gallego, 27 de marzo de 1979. Semprún Guillén, A.: "50 años del 'Jesús del Gran Poder'”, en $A B C$, Madrid, sábado, 24 de marzo de 1979, págs. 13-15, con fotografías.

31 Bugallo, Ánxela: "Amazonia: A atracción do descoñecido", en Iglesias Brage e América. A recuperación dun personaxe para a Historia de Galicia, págs. 40-52.

32 "Francisco Iglesias Brage", biografía aparecida en El Eco, Iquitos (Perú), IX, n. 2.581 , 27 de julio de 1933. 
En estas circunstancias fue designado por la Sociedad de Naciones para formar parte de la Comisión de Administración del Territorio de Leticia.

Pero el comisionado español no era sólo un héroe nacional, famoso en un sector punta de la técnica, como era en aquel momento la aviación, ${ }^{33}$ y muy conocido en América por su proeza; ni tan sólo un gran hombre de empresa, capaz de organizar una gran expedición en la que implicó a todos los organismos de relevancia de su país, y al mismo gobierno, por medio de un patronato oficial, con sus proyectos, presupuestos, publicaciones, etc., y que despertó un enorme entusiasmo entre sus compatriotas. ${ }^{34}$ Era algo más que todo eso, por sus dotes personales, su simpatía, su cultura y su talante abierto y jovial y sus tendencias personales políticamente incorrectas. En Madrid frecuentó al grupo de poetas y escritores que hoy denominamos generación del 27 , y que se reunían a menudo en casa del encargado de la embajada chilena, Carlos Morla, que nos ha dejado una narración $^{35}$ de sus contactos con García Lorca, Manolo Altolaguirre, Vicente Huidobro, Luis Cernuda, María de Maeztu, etc., y de sus recuerdos madrileños. Por cierto que Morla tuvo una actuación humanitaria muy valiente durante la guerra civil a través de su embajada.

En resumen, se trataba de un comisionado muy especial el que acudía a Leticia con el simple rango de capitán de aviación.

\section{Primeras actuaciones de la Comisión}

Al constituirse la comisión de administración como tal, una de sus primeras medidas fue adoptar un título oficial: "Comisión de Administración del Territorio de Leticia"; y una bandera, formada por un rectángulo blan-

33 López Gómez, Pedro: "El Capitán Iglesias, un ferrolano en la historia de la aviación”, en La Voz de Galicia, (I), martes, 27 de marzo de 1979, pág. 48, y (II), miércoles, 28 de marzo de 1979, págs. 20-21.

34 Sobre la Expedición Iglesias al Amazonas, véanse: Crónica de la Expedición Científica al Amazonas. Madrid, 1931. Escrigas, Guillermo: "Iglesias Brage. 'El sueño americano"”, en Ferrol Análisis, 3, junio de 1992, págs. 38-41. Expedición Iglesias al Amazonas. Proyecto definitivo. [Madrid: Vda. de M. De Navarro, 1932], 63 pág., plan. Pleg. (Publicaciones de la Expedición Iglesias al Amazonas, n. ${ }^{\circ}$ 1). Iglesias Brage e América. A recuperación dun personaxe para a Historia de Galicia, citado. Llorca Freire, G.: "Iglesias Brage y la expedición al Amazonas", en Ferrol Diario, 15 de abril de 1979. López Gómez, Pedro: La Expedición Iglesias al Alto Amazonas. (En prensa), Nautilus. "Iglesia Brage y la expedición al Amazonas", en Ferrol Diario, 15 de junio de 1979. Verde, Ana: "As culturas amazónicas obxecto de interese para Iglesias Brage", en Iglesias Brage e América. A recuperación dun personaxe para a Historia de Galicia, págs. 53-62.

35 Morla Lynch, Carlos: En España con Federico García Lorca (Páginas de un diario íntimo, 1928-1939). Madrid, 1957. 
co con la siguiente inscripción en azul obscuro: "Sociedad de NacionesComisión de Leticia". Las tropas puestas a disposición de la Comisión por el gobierno colombiano llevarían como distintivo un brazalete blanco con las letras S D N en azul obscuro sobre su uniforme.

Se determinó que la presidencia fuera rotatoria entre los tres comisarios, y por orden alfabético de países (América del Norte, Brasil, España) y su duración de un mes.

La evacuación del puerto de Leticia y su entrega a la Comisión por el prefecto del departamento de Loreto, César A. Velarde Más, designado a este efecto por el gobierno de Perú, tuvo lugar el día 23 de junio con toda normalidad y, en consecuencia, la Comisión ordenó al coronel Luis Acevedo, que mandaba las fuerzas colombianas puestas a disposición de la Comisión, que se detuviese en Esperanza el vapor que conducía a las tropas y que sólo 50 hombres se trasladasen al vapor Mosquera para continuar hacia Leticia.

Convocados los habitantes de Leticia para establecer con ellos un primer contacto, el capitán Iglesias leyó el acuerdo de 25 de mayo a los 25 habitantes, y al manifestar que sería izada nuevamente la bandera colombiana junto con el distintivo de la Comisión, surgió entre ellos, que eran todos peruanos, un conato de rebeldía que Iglesias sofocó por la persuasión. ${ }^{36}$

Al parecer la población ignoraba los términos del acuerdo entre Colombia y Perú, y los peruanos se sentían preocupados por la posibilidad de que llegasen autoridades colombianas. El ambiente era pro-peruano. El 28 de julio, pocos días después de la llegada de la Comisión a Leticia y de la evacuación del territorio, se sublevaron en Iquitos varios oficiales y suboficiales como protesta contra la posible entrega de Leticia a Colombia. Un oficial —el jefe del movimiento- fue condenado a 20 años de prisión; otros tres oficiales fueron expulsados del servicio; once suboficiales y soldados a penas diversas entre 15 y 1 años de prisión.

Los habitantes de Loreto manifestaban abiertamente que se sentían dispuestos a actuar de nuevo por la fuerza en el caso de que el territorio de Leticia no volviese al Perú en virtud de las negociaciones que se iban a llevar a cabo. Sin embargo, se aceptaba la entrega de los territorios al margen del río Putumayo a Colombia a condición de que el trapecio de Leticia quedase peruano. ${ }^{37}$

36 IB, 146 (1). Comisión de Administración del Territorio. Actas de las sesiones de los días 19 a 24 de junio.

37 IB, 146 (1). Comisión de Administración del Territorio. Actas de las sesiones de los días 1 de julio a 6 de octubre. 
Diversos incidentes ocurridos en julio entre los moradores de Leticia y soldados inclinaron a la Comisión a pedir privadamente al gobierno colombiano la sustitución del coronel Acevedo por no cooperar a la política de la Comisión y no ser grata su autoridad para los moradores; fue reemplazado por el mayor Julio Londoño.

El 24 del mismo mes Iglesias partirá hacia Iquitos, aceptando la invitación del vicecónsul de España, en nombre de la colonia española, a bordo del buque peruano Norona, viaje que tendrá complicadas repercusiones posteriores.

El 8 de agosto la Comisión hizo constar la recepción de un memorial firmado por los habitantes del "Trapecio" en que exponían sus sentimientos y hacían consideraciones e indicaciones respecto a la cuestión de Leticia y el tratado Salomón-Lozano, y se pedía mediante una solicitud firmada por los señores J.E. Giles, Isidro Ruiz, Andrés Fonseca, Alberto Zúñiga, y mil doscientas firmas más, que se entregara a la Sociedad de Naciones..$^{38}$

En el mes de septiembre se produjo el asunto Mencía, y la Comisión, presidida por Iglesias en aquel momento, consiguió de la Sociedad de Naciones que se ordenase a aquél regresar a Ginebra y hacer entrega de la propiedad y archivos de la Comisión, lo que efectuó el 21, partiendo hacia Bogotá el día 25. Esto será el arranque de una violenta campaña contra la Comisión, y especialmente contra Iglesias, que vamos a detallar a continuación. ${ }^{39}$

\section{Las campañas contra Iglesias Brage}

El embajador español en París, Salvador de Madariaga, comunicaba al Ministro de Estado español, en escrito de 23 de octubre, las preocupaciones de la delegación colombiana en Ginebra y en París sobre la actuación de la Comisión de Leticia y especialmente sobre el capitán Iglesias, que se centraban en el choque con Mencía, que tuvo que abandonar el puesto, en la no utilización de las tropas colombianas y en la actitud supuestamente pro-peruana de Iglesias.

El comisario español, el 14 de noviembre, en uno de sus extensísimos escritos, éste al Ministro de Estado, sobre los supuestos anteriores, recusa

38 IB, 148 (1). Memorial apresentado polos habitantes do territorio chamado Trapecio de Leticia à Liga das Naçoes, a raiz da chegada dos membros da comissao, citado.

39 IB, 146 (1). Comisión de Administración del Territorio. Actas de las sesiones de los días 1 de julio a 6 de octubre. 
dichas acusaciones, afirmando haber establecido el orden y haber actuado con imparcialidad, informando de todo ello a la Sociedad de Naciones y al gobierno colombiano, sin que haya tenido queja alguna oficial, actuando siempre mediante acuerdos tomados por unanimidad entre los comisarios, y rehusando la aplicación de una política de fuerza, consiguiendo con ello la tranquilidad del territorio en los cinco meses que duraba su actuación. Según él, la opinión colombiana, el partido conservador en la oposición y parte del liberal en el gobierno, y altos jefes y oficiales del ejército, eran contrarios no a la actuación de la Comisión, sino al acuerdo y a los diplomáticos colombianos que firmaron el tratado, aspirando al uso de la fuerza contra Perú, lo que se manifestaba en la actitud de los jefes de tropa puestos a disposición de la Comisión. El Gobierno, por su parte, se veía obligado a defenderse y mantenía el equívoco de que administraba el territorio por intermedio de la Comisión, lo que, al no ser así, originaba su hostilidad contra ella. La destitución del Dr. Armando Mencía, por su incapacidad y sus relaciones secretas con el funcionario colombiano Dr. Antonio Carvajal, asesor jurídico de la Comisión, retirado de su servicio a petición del comisario comandante Lemos Basto, motivó, fomentada por aquellos, una campaña de prensa contra la Comisión y los comisarios en el diario $E l$ Tiempo, propiedad del Dr. Eduardo Santos, que fue uno de los gestores del acuerdo. En cuanto al uso de un mayor número de fuerzas, sostiene Iglesias que, aparte de provocar al Perú, no ayudaría a las negociaciones entre los dos países en Río de Janeiro. Finaliza Iglesias indicando que las recomendaciones del Gobierno español no pueden ser consideradas por la Comisión, pues sería una intromisión en el mandato que ejercen por la Sociedad de Naciones. Ya veremos cómo esta postura aséptica de Iglesias forzaría su dimisión. ${ }^{40}$

En el mes de noviembre Iglesias realizaría una visita a Bogotá, donde encontró "denso ambiente hostilidad Comisión por fuerte oposición política desarrollada cámara Senado contra Acuerdo Ginebra y campaña prensa realizada por Nieto Caballero contra Comisión y Comisarios particularmente contra mí inspirada por Mencía". ${ }^{41}$ Según informaba el embajador español en Bogotá, Arregui, al Ministro de Estado, Sánchez Albornoz, ${ }^{42}$ las entrevistas de Iglesias con el Presidente y con el Ministro de Relaciones

40 IB, 146 (2). Comisión de Administración del Territorio. Correspondencia. de 1933.

41 IB, 146 (1). Telegrama transcrito en las actas de las sesiones del día 26 de noviembre

42 IB, 146 (2). Comisión de Administración del Territorio. Correspondencia. 
Exteriores disiparon recelos y restablecieron la armonía; no obstante, aparecieron nuevos artículos críticos en El Tiempo con motivo de la llegada del nuevo Secretario de la Sociedad de Naciones, lo que a su entender revelaba un doble juego por parte de los dirigentes colombianos, cuya actitud "vacilante y ambigua" correspondía al "carácter de este pueblo suspicaz, receloso y altivo".

En otro informe al Ministro de Estado, de 11 de diciembre, Iglesias añade a los anteriores comentarios otros sobre las preocupaciones expresadas por el Sr. Santos a Madariaga sobre que él, Iglesias, "no es todo lo imparcial que debiera" por tener como interés predominante su proyecto de expedición al Amazonas, que habría de tener como base inevitable a Iquitos. El capitán español, irritado, dice que "No puede admitirse que el Territorio de Leticia adquiera carácter colombiano por el mero hecho de llenarlo de tropas colombianas... ya que fuera del propio poblado no hay en todo el territorio moradores colombianos que son los que puedan darle principalmente dicho carácter"; en cuanto a la expedición al Amazonas, dice que nadie sabe sus planes, y no se ha dedicado a ellos durante su estancia en Leticia, rechazando las ofertas de ayuda de ambos gobiernos para no herir susceptibilidades; y en cuanto a las bases de la expedición, según el proyecto elevado al Ministro de Intrucción Pública de España en mayo de 1932, y editado y repartido a los Gobierno de Colombia y Perú, se especificaban en él las que serían: 4 en Colombia, 3 en Ecuador, 2 en Brasil y 1 en Perú, Iquitos tan solamente.

Como consecuencia de la campaña, y a pesar de la solidaridad del resto de los miembros de la Comisión, Iglesias presentó su dimisión para salvaguardar su propia dignidad y no continuar envuelto en la atmósfera de hostilidad e injusticia desatada, así como para no entorpecer la labor de la Comisión. ${ }^{43}$

El Gobierno colombiano, preocupado por el curso de los acontecimientos, presionó al Gobierno español para que Iglesias retirase su renuncia, lo que le solicitan también de la Sociedad de Naciones, manifestándole que confiaban en su gestión, ${ }^{44}$ a lo que accede Iglesias, comunicándolo

43 IB, 146 (1). Telegrama de Iglesias al Embajador Arregui, de 13 de diciembre de 1933, y telegrama al Secretario General de la Sociedad de Naciones, n. ${ }^{\circ} 319$, de 13 de diciembre, presentando su renuncia; telegrama de los Comisarios Brown y Lemos Basto al Secretario General de la Sociedad de Naciones, n. $^{\circ} 317$, de 13 de diciembre, apoyando a Iglesias y expresando su temor a que renunciase. Confróntense las Actas de las sesiones del 13 de diciembre de 1933.

44 IB, 146 (1). Telegrama del Secretario de la Sociedad de Naciones, dirigido a Iglesias, del día 16 de diciembre de 1933. Confróntense las Actas del día 18 de diciembre de 1933. 
al Secretariado el día 18, indicando que espera que el Gobierno colombiano hiciera una declaración pública de confianza.

La campaña, sin embargo, continuó. El embajador Arregui, en carta de 7 de diciembre, informa a Iglesias de los nuevos ataques de Mundo al día y El Tiempo, éstos por parte de Guizado y Nieto Caballero, que le presentan como amigo incondicional del Perú, "su mejor abogado defensor", poniendo esta frase en boca del jefe de las fuerzas navales del nor-oriente del Perú, Aurelio de la Guerra, y también de la petición de renuncia que le hace la asustada colonia española de Bogotá. En otra del día 9 le comenta el frenazo en la campaña de prensa y el interés del Ministro de Relaciones Exteriores de que continúe en su comisión hasta el final del mandato, pues se presenta como novedad imprevista la posibilidad de dimisión de Iglesias.

Éste, a consecuencia de toda esta campaña, envía unos informes a Salvador de Madariaga - 9 de diciembre - en los que aporta como novedad sobre lo anterior los ataques que caen sobre la Comisión por el hecho de estar compuesta por militares, incapaces, según dicen, de comprender el espíritu del Acuerdo de Ginebra y todo el enjambre de juridicidad que lo rodea. Incluye una larga queja sobre las deficiencias que ha tenido que soportar la Comisión, no por las condiciones de la región, sino por "la falta de organización con que se llevan a cabo todas las cosas por parte de los colombianos", mencionando expresamente el correo, cuyos retrasos obligaron a la Comisión a utilizar también los correos del Perú por la vía de Iquitos; quejas que se extienden a las personas colombianas que convivían con ellos, que según les habían dicho "por su rango social y su cultura haría grata la vida en Leticia de la Comisión". En cuanto al territorio, afirma que "tiene un marcado carácter peruano. Colombia no tiene aquí raíces ni intereses de ninguna clase... Este trozo, actualmente de Colombia, es una isla en medio de un territorio extranjero"; pero también ve claro que esa cuestión no tiene que ver con la misión de la Comisión, que es "administrar el territorio por mandato de la Sociedad de Naciones en nombre del Gobierno de Colombia... atendiendo de un modo muy especial a mantener el orden en el territorio" ${ }^{45}$ lo que no impide que los Comisarios tengan su juicio personal y reservado del problema de Leticia. En cuanto al ambiente militar,

45 IB, 146 (2). Ya el 4 de diciembre de 1933, la Comisión escribía (n. o 633) al Dr. Pedro María Carreño, encargado del Ministerio de Relaciones Exteriores de Colombia, exponiéndole el criterio de que la Comisión no era delegada del Gobierno de Colombia, reemplazando al intendente, sino que, según el acuerdo de 25 de mayo, el Gobierno de Colombia confió la administración del Territorio a la Sociedad de Naciones para que lo administrase durante un año por medio de la Comisión. Como se ve se trata de dos criterios difícilmente compatibles. 
los oficiales del ejército dicen que, según conversaciones tenidas con ellos en Bogotá, si se entregase Leticia irían a la revolución y se harían cargo del gobierno, pues piensan estar bien preparados sabiendo que no existe comparación posible entre ambos ejércitos, y lo mismo con la aviación y la marina; los peruanos, en caso de guerra, tomarían el islote estratégico de Leticia y la guerra se trasladaría inmediatamente al Pacífico, por lo que convenía definir la actitud de la Sociedad de Naciones al respecto.

Iglesias, pese a la postura del Gobierno colombiano, no se llama a engaño. En carta a Arregui de 22 de diciembre, manifiesta su convencimiento de que fue aquél el iniciador de la campaña contra él, que ha rebasado los términos en que se había encauzado. Considera que todo ha terminado de manera satisfactoria para el Gobierno de Colombia, para el de España y para la Sociedad de Naciones, pero no para él. "Ser imparcial entre Colombia y Perú y a la vez servir determinados intereses que España pueda tener en Colombia es imposible y absurdo... Por esto creo que estoy en un simple compás de espera, ya que más tarde o más temprano esa contradicción se pondrá tan de relieve que yo me veré obligado a presentar nuevamente mi renuncia. Esto sin contar con la posibilidad de que la prensa de Colombia continúe con la actitud ya iniciada".

Su claridad de juicio queda explicitada más ampliamente en el informe n. ${ }^{\circ}$ 4, de 6 de enero de 1934, que envía al Ministro de Estado Español, ${ }^{46}$ contestando una orden reservada dirigida a la Legación, de 21 de octubre de 1933, y recibida en ésta el 11 de diciembre (no olvidemos la lentitud de los correos). En la orden se incluían recomendaciones e instrucciones en relación con el desempeño de la misión de Iglesias, incompatibles a juicio de éste con los deberes del cargo de Comisario, y, a pesar de su deseo y voluntad de servir a la vez los elevados intereses de la patria, estima que no le será posible atender aquellas instrucciones y recomendaciones, pues aunque depende exclusivamente de la Sociedad de Naciones no desea desempeñar su misión sin la aprobación y plena confianza del Gobierno de España, y analiza la situación con una exposición dividida en cuatro puntos que parece importante resumir:

1. ${ }^{\circ}$ Sobre la misión de la Comisión de Leticia, y respecto a lo que dice el Ministro de que "la finalidad esencial de la misma es la restauración de la soberanía colombiana en Leticia", esta insistencia del Ministerio en fijar la interpretación del mandato dado a la Comisión supone una ignorancia inad-

46 IB, 146 (3). Comisión de Administración del Territorio. Correspondencia. 
misible, y además, el criterio del Gobierno de España es erróneo, pues la misión de la Comisión es simplemente administrar el territorio de Leticia.

2. ${ }^{\circ}$ Sobre política internacional de España en América, que afirma el Ministro "es de absoluta neutralidad en los conflictos", él estimaba que la solicitud española de entrar en la Comisión suponía entrar en la cuestión a fondo, detallando el clima prebélico existente entre los dos países contenciosos y sus causas, y afirma que aún cuando los Comisarios no entren a discutir el problema de fondo que supone el conflicto de Leticia, España corre el riesgo de que la opinión pública de uno de estos países se sienta resentida y dolorida por su intervención, por lo que el Gobierno español debió abstenerse de proponer un delegado español, pero pesó más en el ánimo del Gobierno el realizar un acto de simpatía hacia Colombia.

3..$^{\circ}$ Sobre la política de España respecto a Colombia, el Gobierno quiere desvanecer la mala impresión causada por la negativa a vender el crucero "Dato", llevando una política de aproximación a este país, de lo que Iglesias deduce que España tuvo especial empeño en intervenir en el conflicto de Leticia en el momento en que su intervención podía ser grata a los colombianos, es decir, en el momento en que por el Acuerdo de Ginebra se reconocían sus derechos sobre dicho territorio, y se encargaba - según la creencia del Gobierno español— de reintegrarlo la Comisión a Colombia, razón de más para haberse inhibido de la cuestión y no intervenir en la actuación de la Comisión, como no lo han hecho ni Brasil ni Estados Unidos.

4. ${ }^{\circ} \mathrm{Y}$ en cuanto a las recomendaciones para el desempeño de su labor, que debe revestirse de la máxima neutralidad e imparcialidad absoluta, al aceptar el cargo, el Subsecretario del Ministerio de Estado le manifestó a él personalmente que no dependía del Gobierno de España, sino de la Sociedad de Naciones, y que no consideraba oportuno darle instrucciones ni sugerencias de ningún género, criterio que se ha seguido durante cuatro meses y que no se sigue en ese momento. Considera que es imposible ser justo e imparcial y atender la política de simpatía y aproximación entre España y Colombia.

La postura de Iglesias era íntegramente apoyada por Arregui, quien le dice comentando su escrito: "me parece una catilinaria admirable contra el Sr. Sánchez Albornoz (¡que lástima que no esté, ya en Estado... para ese solo efecto!) y sus erróneos puntos de vista con respecto a la actitud que debe adoptar España en el litigio colombo-peruano". ${ }^{47}$

47 IB, 146 (3). Carta de Arregui a Iglesias de 12 de enero de 1934. 
Mientras tanto, la Comisión continúa sus tareas. El 10 de enero de 1934 se plantea la fecha final de su mandato, que estima debe ser el 23 de junio, y para entonces, y con instrucciones de la Liga para ello, debería dejarse provista a Leticia del número de fuerzas colombianas que el Gobierno colombiano estimara precisas, 15 días antes de abandonar la Comisión el territorio. El Archivo debía ser enviado a Ginebra; y los trabajos pendientes deberían estar finalizados para entonces; se trataba de trabajos públicos de higiene y vías de comunicación, que daban ocupación a trabajadores de la zona, y del censo de población del territorio.

Llegan entre tanto, con retraso debido al correo, nuevas órdenes del Ministro de Estado, fechadas el 26 de diciembre de 1933, firmadas por Leandro Pita Romero, que constituyen un modelo de impertinencia y patriotería. La contestación de Iglesias se hace más radical, y tras recordar que no puede ni debe convertirse en el representante oficioso de España, y rechazar los planteamientos respecto al aumento de tropas en el territorio, pues con ello no se evitará el choque armado si fracasan las negociaciones entre los dos países, acepta que si se produjese tal choque se señalaría a la Comisión y a él en particular como responsables, responsabilidad que puede recaer en España, consecuencias previsibles si se hubiera estudiado a fondo la cuestión de Leticia, por todo lo cual presenta su renuncia.

Una nueva campaña difamatoria de prensa se desató por estas fechas en El Tiempo y El País contra Iglesias como agente entregado al servicio de la nación vecina; aunque el Ministerio de Relaciones Exteriores desmiente este supuesto, Iglesias comunica oficialmente su dimisión. Arregui se solidarizó con él y con su actuación en Leticia, y planea marcharse del país, por el comportamiento del Gobierno español y su política de contemplaciones absurdas y asqueado -dice- por el comportamiento del Gobierno colombiano que justificaba los editoriales contra Iglesias en que "la oficina de censura de Prensa del Ministerio de la Guerra estaba cerrada por la tarde y por ello no pudo evitarse que El Tiempo publicara el primer artículo agresivo". La dimisión de Iglesias no fue hecha pública en Bogotá hasta el día 16, desde el 10.

Naturalmente, a partir de este momento llueven los elogios y las felicitaciones sobre él, algunas tan curiosas como la de Román Casas: "El más humilde de los españoles le suplica no rebocar (sic) su renuncia; jamás hará nada satisfactorio por el solo hecho de ser español. Regrese a la madre patria donde sí le saben preciar lo que vale". 
Nuevas presiones para que retirase su dimisión fueron rechazadas con dignidad por Iglesias. El nuevo delegado español será un tal Giráldez.

El secretario de la Comisión, García Palacios, en un informe de 1 de abril de 1934 al Sr. Walters, Subsecretario General de la Sociedad de Naciones, afirmaba "que quería dejar claro que el capitán Iglesias ha sido la víctima expiatoria de la lucha de partidos en Colombia. El Partido Conservador, que ataca constantemente el acuerdo de Ginebra ha encontrado en él su víctima para lanzar sus dardos contra el partido liberal que está en el poder actualmente. Se ha jugado a la ligera con el honor de un hombre que se ha entregado a su tarea con todo su ardor, su inteligencia, su comprensión del problema y su gran lealtad". ${ }_{48}$

\section{Etapa final de la Comisión de Administración}

Iglesias había polarizado, por lo fuerte de su personalidad, toda la atracción de las diversas tensiones existentes en torno a Leticia; su marcha sólo sirvió para desvelarlas con más claridad.

Una reparación de última hora se le hizo indirectamente, al cesar la Secretaría de la Sociedad de Naciones a Mencía en su cargo, por decisión unánime de los cuatro miembros del Comité Judicial de la Secretaría, de acuerdo con las normas de personal, y por su conducta, lo que se comunicó a los miembros de la Comisión de Leticia por T. Azcárate, el 24 de enero de 1934.

Por su parte, García Palacios, que continuó carteándose con Iglesias, también fue difamado en un libro escrito por el antiguo secretario de la Legación colombiana en Buenos Aires, acusándole de peruanofilia, lo que produjo en Iglesias "una verdadera sensación de consuelo al comprobar que la conducta de la mayoría de los colombianos con la Comisión fue un tanto rastrera". Iglesias hacía una serie de consideraciones al leer en el Diario Oficial de la Sociedad de Naciones de julio de 1934 los informes de la Comisión, redactados casi íntegramente por él —excepto el final—, al ver rectificadas las declaraciones sobre sus entrevistas con el Presidente de la República, Olalla Herrera, que le llenan de indignación, y comprobar que no se incluye el informe que dejó escrito a la Comisión a la salida del trapecio, y afirmaba "que Colombia había cumplido el acuerdo de Ginebra

48 IB, 146 (3). 
como le daba la gana; y otra, que la Sociedad de Naciones y la Comisión, que era su representante, no habían tenido fuerza moral ni material para imponerse al Gobierno de aquel país". ${ }^{49}$

\section{Epílogo}

Después de su dimisión, Iglesias efectuó un largo y sosegado viaje por el Amazonas abajo, dedicándose a recoger utensilios etnográficos y ejemplares de fauna y flora amazónicas, ${ }^{50}$ en cuya catalogación contó con la ayuda experta del Director del Museo Comercial de Belem de Pará, Mr. Paul Leccinte; y de una colección de animales (serpientes, aves, felinos, etc.), adquirida en Leticia y engrosada en Manaos, que descansaron más de un mes en el magnífico parque zoológico del Museo Goeldi, y que perecieron en gran parte en el posterior viaje hacia España, pasando el resto al Parque Zoológico de Madrid.

En esta ciudad montó una

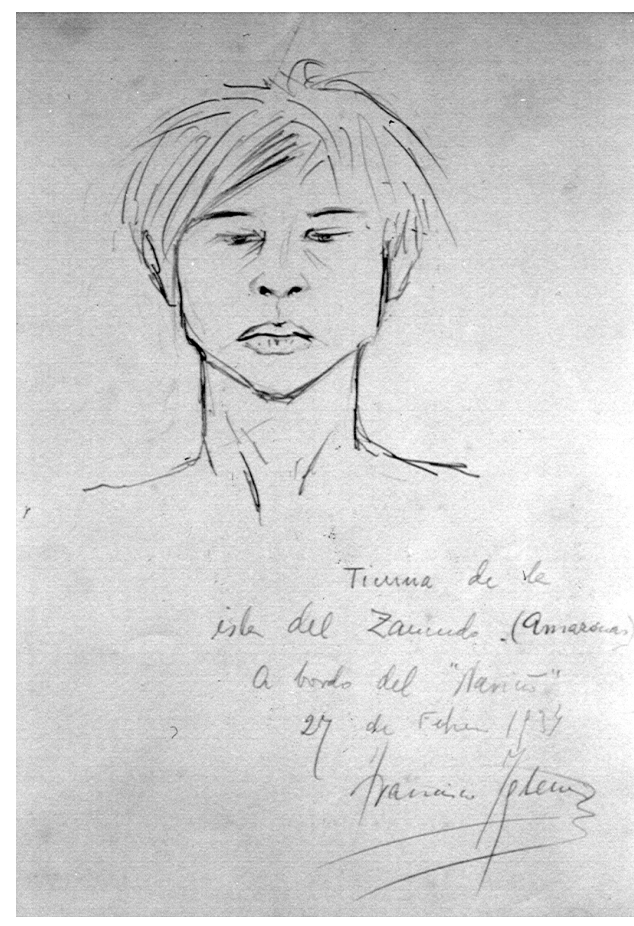

Retrato de indio Ticuna de la isla del Zancudo, en el río Amazonas / Francisco Iglesias. [s.l.: s.n.], 27 febrero 1934. Dibujo realizado a bordo del "Nariño". ARG, CC, IB, 294.

gran exposición de etnografía amazónica, ${ }^{51}$ que tuvo un éxito enorme, y que contribuyó a extender el interés por los preparativos de la expedición que se organizaba bajo la protección del Gobierno de la República, y que tendría que suspenderse por la crisis político-económica previa a la Guerra Civil del 36.

49 IB, 146 (3).Carta a García Palacios de 25 de abril de 1935.

50 Verde, Ana: "As culturas amazónicas obxeto de interese para Iglesias Brage”, págs. 53-62.

51 Exposición Iglesias de Etnografía Amazónica (prólogo de Francisco Iglesias Brage). Madrid, Sociedad Española de Amigos del Arte, 1935. 
En cuanto a las conversaciones entre Colombia y Perú, el 25 de mayo de 1934, un año después del acuerdo de Ginebra, los dos países firmaban un acuerdo en Río de Janeiro por el que se reanudaban las relaciones diplomáticas, rotas a raíz de los sucesos de Leticia; se reconocía el tratado de límites de 1922 como uno de los vínculos jurídicos que les unía; se planteaba la desmilitarización de la frontera; se creaba una comisión mixta de tres miembros, con la inclusión de Brasil; y se establecía la libertad de navegación fluvial entre los ríos comunes para los dos países, con la creación de un sistema aduanero especial. ${ }^{52}$

52 El Comercio, Lima, 26 de mayo de 1934, reprodujo íntegramente el tratado. 


\section{Anexo: el archivo del coronel Iglesias Brage}

Este fondo documental, de singular importancia, reflejo de la que tuvo su propietario, formaba parte en realidad de un conjunto mayor, integrado, además, por su Biblioteca y su Colección etnográfica, ${ }^{53}$ todo ello muy valioso en relación a la Historia Contemporánea de América. El Archivo fue depositado inicialmente en el Archivo Histórico Provincial de Pontevedra (AHP-Po), en espera de que finalizaran los lentos trámites administrativos para su adquisición, por parte del Estado, a sus herederas, con la intención de incorporarlo a este Centro, lo que se efectuó en 1983. Posteriormente, en 1992, pasó, por intercambio, al Archivo del Reino de Galicia (ARG), en la ciudad de A Coruña, donde se custodia en la actualidad.

Está formado por 158 legajos, con documentos de los años 1911 a $1972^{54}$ a los que hay que añadir las colecciones iconográficas y cartográficas (516 títulos), fotográficas (sin cuantificar) y algunos documentos de procedencia incierta que forman colección documental separada.

La identificación de sus documentos dio origen a una organización y clasificación inicial, ${ }^{55}$ y que serviría de base para la definitiva, que es la siguiente:

\section{Clasificación de los fondos del Archivo del Coronel Francisco Iglesias Brage ${ }^{56}$}

\section{FONDO DOCUMENTAL \\ 1.1. DOCUMENTOS PERSONALES \\ 1.1.1. BIOGRÁFICOS \\ 1.1.2. DE IDENTIFICACIÓN PERSONAL \\ 1.1.3. DE CARÁCTER HONORÍFICO \\ 1.1.4. DE NOMBRAMIENTOS E INCIDENCIAS \\ 1.1.5. DE ESTADO DE SALUD \\ 1.2. ESTUDIOS \\ 1.2.1. ACADÉMICOS \\ 1.2.2. FORMACIÓN PROFESIONAL CONTINUADA}

53 Informe sobre las colecciones que pertenecieron a don Francisco Iglesias Brage, Coronel de Aviación. Pontevedra, 16 de mayo de 1978. Archivo de la Secretaría del Archivo Histórico Provincial de Pontevedra (AHP-PO).

54 Archivo del Reino de Galicia. Página web: http://www.xunta.es/conselle/cultura/patrimonio/ arquivo\%20reino/index.htm.

55 López Gómez, Pedro: El Archivo del Coronel Francisco Iglesias Brage: Esquema de clasificación. Junio, 1981, 25 fol. mec.

56 López Gómez, Pedro: "O Arquivo do coronel don Francisco Iglesias Brage", en Iglesias Brage e América. A recuperación dun personaxe para a Historia de Galicia, págs. 11-20. 
PEDRO LÓPEZ GÓMEZ

1.3. PATRIMONIO

1.3.1. PROPIEDADES

1.3.2. ADMINISTRACION

1.4. FUNCIÓN PÚBLICA

1.4.0. LEGISLACIÓN SOBRE PERSONAL

1.4.1. UNIDAD DE ZAPADORES

1.4.2. OBSERVADOR DEL GRUPO ESCUADRILLAS DE MELILLA

1.4.3. OFICINA CENTRAL DE INTERVENCIÓN Y TROPAS JALIFIANAS DE MELILLA

1.4.4. AVIACIÓN MILITAR. FUERZAS DE LA ZONA ORIENTAL.

1.4.5. SERVICIOS DE MATERIAL: INSPECTOR DE FABRICACIÓN DE GETAFE

1.4.6. CONSTRUCCIONES AERONÁUTICAS O HISPANO-SUIZA DE GUADALAJARA

1.4.7. ESCUELA DE TRANSFORMACIÓN DE GUADALAJARA

1.4.8. INSPECTOR DE LA ESCUELA CIVIL DE PILOTOS DE ALBACETE

1.4.9. ESCUADRILLA DE BREGUETS / FUERZAS AÉREAS DEL NORTE

1.4.10. JEFE DE LA ESCUELA DE ESPECIALISTAS DE MÁLAGA

1.4.11. SECRETARÍA GENERAL Y TÉCNICA DEL MINISTERIO DEL AIRE

1.4.12. REGIÓN AÉREA ATLÁNTICA

1.4.12.1. JEFATURA DE OBRAS DEL SECTOR AÉREO DE GALICIA

1.4.12.2. JEFATURA DE LA ZONA TERRITORIAL DE INDUSTRIA N. ${ }^{\circ} 7$

1.4.13 DIRECCIÓN GENERAL DE AEROPUERTOS

1.4.14. IBERIA

1.4.14.1. SUBDIRECCIÓN DE MATERIAL

1.4.14.2. TABSA (Talleres Aeronáuticos Barajas, S.A.)

1.5. FUNCIONES PRIVADAS

1.5.1. ASOCIACIONES

1.5.1.1. PROFESIONALES

1.5.1.2. CIENTÍFICAS

1.5.1.3. RECREATIVAS

1.5.1.4. DEPORTIVAS

1.5.1.5. POLÍTICAS

1.5.1.6. RELIGIOSAS

1.5.2. ACTIVIDADES CIENTÍFICO-PROFESIONALES

1.5.2.1. VUELO DEL "JESÚS DEL GRAN PODER"

1.5.2.2. EXPEDICIÓN AL AMAZONAS

1.5.2.3. COMISIÓN DEL AÑO POLAR

1.5.2.4. COMISIÓN DE LETICIA

1.5.2.5. IV CENTENARIO DEL DESCUBRIMIENTO DEL AMAZONAS

1.5.3. ACTIVIDADES LITERARIAS

2. SERIES FACTICIAS

2.1. SERIE FACTICIA DE MAPAS Y PLANOS

2.2. SERIE FACTICIA DE FOTOGRAFÍAS

3. COLECCIONES DOCUMENTALES

608

Anuario de Estudios Americanos 
Toda esta documentación está inventariada, ${ }^{57}$ y se han realizado índices onomásticos de las diferentes series de expedientes personales y correspondencia. Las colecciones cartográficas están catalogadas en gran medida, al menos las piezas relativas a América, ${ }^{58}$ pero no así las fotográficas, con la excepción de aquellas piezas seleccionadas para exposiciones. ${ }^{59}$

De todos estos documentos se han de señalar como especialmente interesantes para la historia de América los agrupados bajo los epígrafes de: Leticia, que son el soporte de este trabajo, los de la Expedición al Amazonas, ${ }^{60}$ y los del $I V$ Centenario del Descubrimiento del Amazonas, que tienen su complemento natural en los mencionados documentos especiales, sobre todo en las colecciones de fotografías, y de mapas y planos.

Hemos utilizado para este trabajo, sobre todo, actas y comunicados de la Sociedad de Naciones relativas a Leticia, documentos elaborados por la Comisión de Administración del Territorio, en especial actas, correspondencia e informes del Presidente y Comisionados, sobre todo y como es lógico del propio Iglesias, y, además, diversos impresos como folletos, hojas sueltas, periódicos y artículos de prensa que versan sobre el mismo sujeto, contenidos en su mayoría en los legajos 145 a 148, que se agrupan bajo la rúbrica LETICIA.

El complemento del Archivo Iglesias, en todo lo referente a Leticia, está, como es de suponer, en los Archivos de la Sociedad de Naciones, en Ginebra, en los Archivos de los Ministerios de Asuntos o Relaciones Exteriores de los países implicados en el conflicto, como son Colombia, Perú y Brasil, y en menor grado, en España y Estados Unidos, y en los Archivos locales (notarías, registros de la propiedad, ayuntamientos, etc.) de Leticia e Iquitos, así como en la prensa de la época, en particular de estas dos ciudades. En otros muchos archivos históricos y administrativos, del Estado y de instituciones científicas y docentes pueden localizarse documentos complementarios de los citados. ${ }^{61}$

57 Archivo del Reino de Galicia. Inventario del Archivo del Coronel Francisco Iglesias Brage [Pedro López Gómez y Mariola Suárez Rodríguez]. S.1., s.a, 73 f. ordenador. Sig. L.55

58 Archivo del Reino de Galicia. Guía de fuentes para la Historia de América en el Archivo del Reino de Galicia. Tomo I [dirección Pedro López Gómez]. [Santiago de Compostela], Dirección Xeral do Patrimonio Histórico e Documental, D.L. 1995, 320 págs.; il. Contiene: I. Generalidades.II. Fuentes documentales textuales [Beatriz Díaz Vázquez, Pedro López Gómez].--III. Documentos cartográficos [Olimpia López Rodríguez].

59 Iglesias Brage e América. A recuperación dun personaxe para a Historia de Galicia, citado.

60 En realidad se trata del Archivo de la Secretaría de la propia Expedición, que debió quedar en manos de Iglesias al iniciarse la Guerra Civil de 1936-39.

61 Martínez García, Luis: "Fontes documentais sobre Iglesias Brage nas institucións pùblicas", en Iglesias Brage e América. A recuperación dun personaxe para a Historia de Galicia, págs. 99-100. 